\title{
Effectiveness of different targeted temperature management methods for fever in patients with acute cerebral infarction.
}

\author{
Xiaomei Zhang, Qindi Zhang, Chunlan Zhou, Taosheng Deng, Yafang Zhu, Meng Cao, Suyue Pan* \\ Department of Neurology, Nanfang Hospital, Southern Medical University, Guangzhou North Avenue 1838\#, \\ Guangzhou 510515, P.R. China.
}

\begin{abstract}
Objectives: To observe the effectiveness of different targeted temperature management (TTM) methods in patients with acute cerebral infarction (ACI) and explore the most feasible cooling strategies for ACI.

Methods: We retrospectively analyzed the effectiveness of different TTM strategies for ACI patients treated in the Neuointensive Care Unit of South Hospital of Southern Medical University from June 1, 2012 to May 31, 2015. Patients were divided into four groups according to the presence or absence of fever and the cooling method: control group $(n=63$, normal body temperature), group $A$ (ibuprofen alone, $n=53$ ), group $B$ (ice bag alone, $n=49$ ), and group $A B$ (ibuprofen + ice bag, $n=62$ ). We measured rectal temperature at admission and $1 \mathrm{~h}, 2 \mathrm{~h}, 4 \mathrm{~h}, 6 \mathrm{~h}$, $12 \mathrm{~h}, 48 \mathrm{~h}$ and $72 \mathrm{~h}$ after admission in the control group. In groups $\mathrm{A}, \mathrm{B}$, and $\mathrm{AB}$, we measured rectal temperature immediately after cooling and $1 \mathrm{~h}, 2 \mathrm{~h}, 4 \mathrm{~h}, 6 \mathrm{~h}, 12 \mathrm{~h}, 48 \mathrm{~h}$, and $72 \mathrm{~h}$ after cooling.

Results: Body temperature showed no significant difference immediately after cooling among groups $\mathrm{A}, \mathrm{B}$, and $\mathrm{AB}(\mathrm{P}>\mathbf{0 . 0 5})$; however, cooling effectiveness was significantly different at multiple time points after cooling $(\mathbf{P}<\mathbf{0 . 0 5})$. Body temperature decrease was greater in group $A$, in which cooling effectiveness was more obvious. During cooling, body temperature in group B was slightly lower than that in group A, but the difference was not statistically significant. After cooling, body temperature decrease was significantly greater in group $A$ than in groups $B$ and AB (P<0.05).
\end{abstract}

Conclusion: For ACI patients, ibuprofen alone is superior to ice-bag cooling or ibuprofen + ice bag cooling.

Keywords: Acute cerebral infarction, Fever, Targeted temperature management, Cooling.

Accepted on June 02, 2017

\section{Introduction}

Acute cerebral infarction (ACI) is a common critical illness, with relatively high disability and case-fatality rates [1]. ACI patients are often accompanied with consciousness disturbances, swallowing dysfunction, limb dysfunction, and in dwelling of a variety of invasive catheters, which can easily lead to infections. Infection is the main cause of early fever in ACI patients [2,3]. In addition, fever may also be associated with necrosis and edema secondary to infarction or hemorrhage [4]. In the pathogenesis of fever following ACI, the ischemic infarction often involves the hypothalamus; the hypothalamic ischemic injury can cause the damage of the temperature-regulating center, resulting in central fever, which is another key factor in the early fever of ACI. [5]. Animal studies have demonstrated that fever is a risk factor for the worsening of ischemic cerebrovascular disease, and such harmful effect can persist even within several days after the ischemia [6,7]. In addition, clinical studies have also revealed that fever is an independent risk factor of the poor prognosis of stroke and is closely associated with mortality and cerebral infarct volume [8,9]. Central fever occurring early will further aggravate the condition, reduce the level of prognosis of patients [10,11]. Therefore, for ACI patients requiring proactive prevention and control of infections, controlling the increase of body temperature may be helpful to improve the prognosis.

In our current study, by comparing the use of different targeted temperature management (TTM) methods, which included ibuprofen cooling (a drug cooling method) and ice-bag cooling (a physical cooling method), in ACI patients, we tried to identify a safe and effective therapeutic hypothermia method.

\section{Methods}

\section{Subjects}

A total of 227 ACI patients in the Neurointensive Care Unit of South Hospital of Southern Medical University from June 1, 2012 to May 31, 2015 were enrolled in this retrospective study. Through consulting the patient's records where previously treated by others, patients were divided into four groups according to the presence or absence of fever and the specific TTM method applied: control group $(n=63$, with normal body 
Citation: Pan S, Zhang X, Zhang Q, et al. Effectiveness of different targeted temperature management methods for fever in patients with acute cerebral infarction. J Neurol Neurorehabil Res. 2017;2(2):10-14.

temperature), group A (ibuprofen alone, $n=53$ ), group B (ice bag alone, $\mathrm{n}=49$ ), and group AB (ibuprofen + ice bag, $n=62$ ).

\section{Ethical review}

This study has been approved by the ethics committee of our center. Written and verbal informed consent was obtained from all patients' caregivers.

\section{Inclusion criteria}

All patients were aged $\geq 18$ years and were hospitalized within $48 \mathrm{~h}$ of disease onset. The rectal temperature and other statistical data were recorded at admission. ACI was definitely diagnosed and the ischemic ACI was confirmed by brain CT or MRI. The rectal temperature was below $38^{\circ} \mathrm{C}$ in the control group. In group A, the rectal temperature was $\geq 38^{\circ} \mathrm{C}$ within $48 \mathrm{~h}$ after admission, and ibuprofen cooling alone was applied during admission. In group B, the rectal temperature was $\geq 38^{\circ} \mathrm{C}$ within $48 \mathrm{~h}$ after admission, and ice-bag cooling alone was applied during admission. In group $\mathrm{AB}$, the rectal temperature was $\geq$ $38^{\circ} \mathrm{C}$ within $48 \mathrm{~h}$ after admission, and both ibuprofen and icebag cooling methods were applied during admission (without using other cooling methods).

\section{Exclusion criteria}

Patients with the following conditions were excluded: transient ischemic attack (TIA); recovery period or sequelae of acute cardiovascular disease (ACVD); cerebral infarction caused by subarachnoid hemorrhage and trauma; lack of clinical data on body temperature and other required information; and use of cooling methods other than ibuprofen and ice-bag cooling.

\section{Statistical analysis}

Data were processed using SPSS 19.0 software. Two independent-samples t-test and one-way ANOVA were applied for the comparisons of normally distributed measurement data among groups; for non-normally distributed measurement data, non-parametric Wilcoxon rank sum test was used. The intergroup comparisons of the count data were performed using the 2 tests. A value of $\mathrm{P}<0.05$ was considered statistically significant.

\section{Results}

\section{General data}

Totally 457 ACI patients were treated in our center from June 1, 2012 to May 31, 2015. After 49 patients with incomplete clinical data and 181 patients who had used cooling methods other than ibuprofen and ice-bag cooling were excluded, 227 patients entered the final analysis. The four groups showed no significant difference in terms of age, sex, location of infarction, infarct volume, high-risk factors, indwelling catheter, infection type, ibuprofen dosage, frequency of administration, Glasgow Coma Scale (GCS) scores and National Institute of Health stroke scale (NIHSS) scores at admission. The TTM effectiveness was comparable among these four groups in Table 1.

Drug cooling and physical cooling are two commonly used TTM strategies in clinical settings, and both strategies have many different cooling methods. In our current study, the body temperature at admission and $1 \mathrm{~h}, 2 \mathrm{~h}, 4 \mathrm{~h}, 6 \mathrm{~h}, 12 \mathrm{~h}, 48 \mathrm{~h}$, and $72 \mathrm{~h}$ after admission were measured in the control group. In groups $\mathrm{A}, \mathrm{B}$, and $\mathrm{AB}$, the body temperature immediately after cooling and $1 \mathrm{~h}, 2 \mathrm{~h}, 4 \mathrm{~h}, 6 \mathrm{~h}, 12 \mathrm{~h}, 48 \mathrm{~h}$, and $72 \mathrm{~h}$ after cooling were measured. The body temperature showed no significant difference immediately after cooling among groups A, B, and $\mathrm{AB}(\mathrm{P}>0.05)$; however, the cooling effectiveness was significantly difference in multiple time points after cooling $(\mathrm{P}<0.05)$.

The drop of body temperature was larger in group A, in which the cooling effectiveness was more obvious. During cooling, the body temperature in group B was slightly lower than that in group A but the difference was not statistically significant; after cooling, the drop of body temperature was significantly larger in group $\mathrm{A}$ than in groups $\mathrm{B}$ and $\mathrm{AB}(\mathrm{P}<0.05)$ (Figure 1).

\section{Discussion}

Body temperature is positively correlated with oxygen consumption and blood flow of the brain. When the body temperature drops by $1{ }^{\circ} \mathrm{C}$, the brain oxygen consumption and blood flow will decrease by $6.7 \%$ [12]. Fever aggravates brain damage and thus affect the prognosis and even endanger the patients; thus, TTM for ACI patients with fever is particularly

Table 1. Characteristics of four groups of patients with acute stroke.

\begin{tabular}{|c|c|c|c|c|c|c|}
\hline \multirow{2}{*}{ Variables } & \multicolumn{4}{|c|}{ Groups } & \multirow[b]{2}{*}{$\mathrm{F} / \mathrm{X} 2$} & \multirow[b]{2}{*}{$\mathbf{P}$} \\
\hline & Group A & Group B & Group AB & Group AB & & \\
\hline Age (years), mean $\pm S D$ & $63.94 \pm 8.67$ & $62.20 \pm 9.60$ & $66.02 \pm 7.25$ & $64.41 \pm 8.62$ & 1.940 & 0.124 \\
\hline Infarct area & $\begin{array}{c}32.60 \\
(30.20,35.05)\end{array}$ & $\begin{array}{c}33.20 \\
(30.80,35.90)\end{array}$ & $\begin{array}{c}34.00 \\
(32.20,36.20)\end{array}$ & $\begin{array}{c}34.20 \\
(31.50,35.80)\end{array}$ & 6.534 & 0.088 \\
\hline CRP & $\begin{array}{c}18.00 \\
(12.00,24.00)\end{array}$ & $\begin{array}{c}22.00 \\
(14.00,32.00)\end{array}$ & $\begin{array}{c}19.00 \\
(12.00,27.00)\end{array}$ & $\begin{array}{c}22.00 \\
(14.00,37.00)\end{array}$ & 5.095 & 0.165 \\
\hline РCT & $\begin{array}{c}0.08 \\
(0.05,0.13)\end{array}$ & $\begin{array}{c}0.08 \\
(0.05,0.11)\end{array}$ & $\begin{array}{c}0.08 \\
(0.05,0.14)\end{array}$ & $\begin{array}{c}0.10 \\
(0.08,0.12)\end{array}$ & 4.535 & 0.209 \\
\hline GCS score,median (IQR) & $\begin{array}{c}9.00 \\
(8.00,11.00)\end{array}$ & $\begin{array}{c}9.00 \\
(8.00,11.00)\end{array}$ & $\begin{array}{c}9.00 \\
(8.00,11.00)\end{array}$ & $\begin{array}{c}9.00 \\
(8.00,11.00)\end{array}$ & 2.639 & 0.451 \\
\hline NIHSS score,median (IQR) & $\begin{array}{c}17.40 \\
(6.00,38.00)\end{array}$ & $\begin{array}{c}18.65 \\
(6.00,34.00)\end{array}$ & $\begin{array}{c}19.02 \\
(4.00,31.00)\end{array}$ & $\begin{array}{c}17.14 \\
(4.00,31.00)\end{array}$ & 0.028 & 0.867 \\
\hline WBC,median (IQR) & $\begin{array}{c}8.90 \\
(7.75,11.30)\end{array}$ & $\begin{array}{c}9.82 \\
(7.60,11.16)\end{array}$ & $\begin{array}{c}9.06 \\
(7.65,10.83)\end{array}$ & $\begin{array}{c}9.00 \\
(7.79,11.21)\end{array}$ & 0.327 & 0.955 \\
\hline Ibuprofen dosage (ml) & $\begin{array}{c}77.69 \\
(60.90)\end{array}$ & -- & $\begin{array}{c}76.94 \\
(60,90)\end{array}$ & -- & 0.209 & 0.649 \\
\hline Frequency of administration & $\begin{array}{c}0.36 \\
(8.00,12.00)\end{array}$ & -- & $\begin{array}{c}10.26 \\
(8.00,12.00)\end{array}$ & -- & 0.209 & 0.649 \\
\hline
\end{tabular}




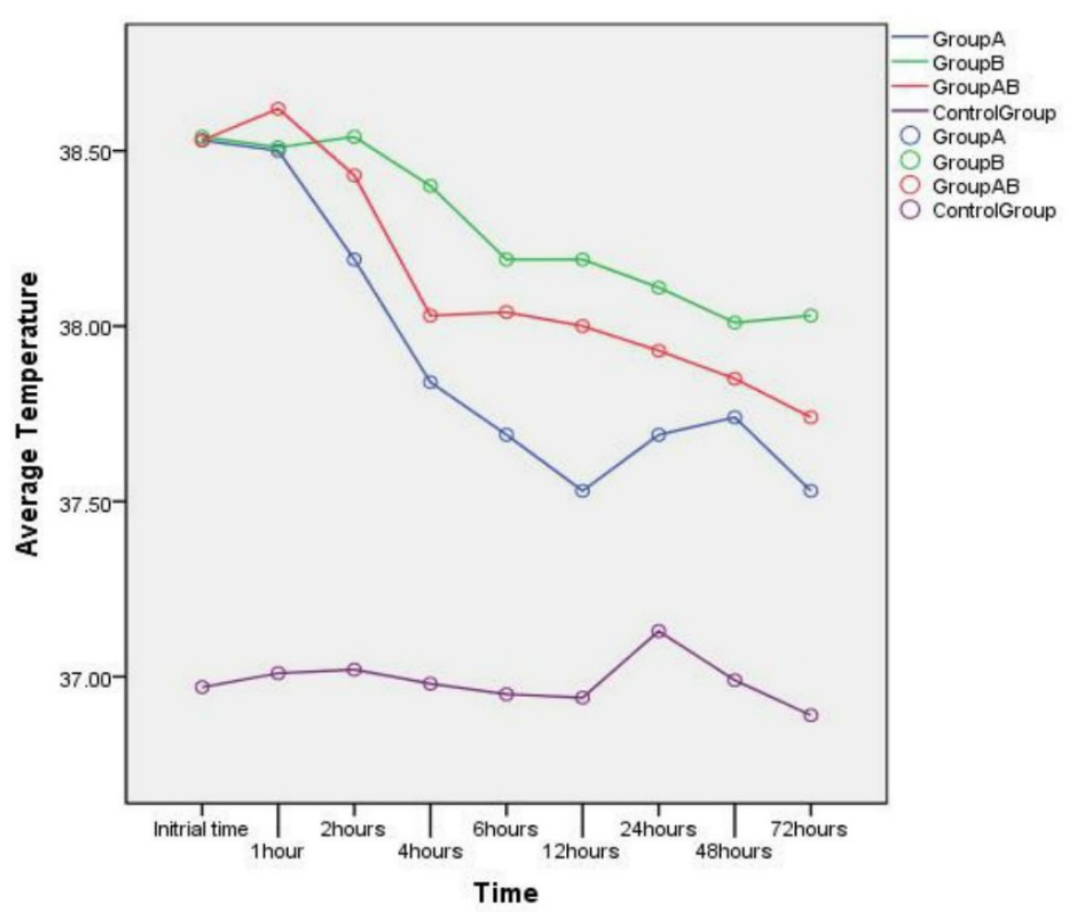

Figure 1. Changing trend of the cooling effectiveness among the four groups.

important in clinical settings. Although the effectiveness of TTM in ACI patients have been well recognized in recent years, this technology has not been widely applied due to its high requirements on equipment, invasiveness of the operation, and low awareness among patients and their families [13]. Brain tissue damage caused by fever is a complicated process, which is currently explained by the following mechanisms: a) The levels of some excitatory neurotransmitters such as glutamate, gamma-aminobutyric acid (GABA), and glycine increase with high body temperature and decrease with low temperature $[14,15]$, and when at high levels they can aggravate brain injury; b) hypothermia can reduce free radical production, whereas hypothermia increases free radical 124 production and thus leads to late neuronal death [16]. c) in animal experiments, the amount of protein cross blood brain barrier decreased at low body temperature $\left(30^{\circ} \mathrm{C}\right.$ to $\left.33^{\circ} \mathrm{C}\right)$ and increases at high body temperature $\left(39^{\circ} \mathrm{C}\right)$ [17]. d) Hypothermia reduces cerebral metabolic rate [18], and thus decreases lactate accumulation following ischemia; in contrast, hyperthermia aggravates lactic acidosis and promotes neuronal death [19]. In a meta-analysis on the prognosis of similar patients in 39 studies, DM Meta et al found that fever patients with ischemic stroke, hemorrhagic stroke, or traumatic brain injury had relatively higher disability rate and case-fatality rate, longer ICU stay and prolonged hospitalization [20]. Therefore, for patients with ACI, body temperature, appropriate increase in body temperature may be allowed, and rational TTM measures should be taken to cool the body temperature. In our current study, the patients' body temperature was above $38^{\circ} \mathrm{C}$ (and even $39^{\circ} \mathrm{C}$ ) when the cooling method was initiated.

Currently, the commonly used cooling strategies include drug cooling and physical cooling. Non-steroidal anti-inflammatory drugs (NSAIDs) are the mainstream drugs used for therapeutic hypothermia. As an NSAID, ibuprofen is initially used as an antipyretic drug for children due to its high safety [21]. The common physical cooling methods in clinical settings include ice bag, alcohol sponge bath, medical cooling blanket, and intravascular cooling; many studies have demonstrated the effectiveness of these methods. In particular, ice bag has been widely applied due to its simplicity and affordability. Therefore, in our current study, we retrospectively compared the cooling effectiveness of three methods: ibuprofen alone, ice bag alone, and ibuprofen + ice bag.

Fever is a complex physiological reaction, and its clinical stages mainly include: temperature rise, high fever, and temperature drop. Heat production is larger than heat loss during the temperature rise; ice-bag cooling during this stage may lower the local body surface temperature, which lead to increased heat production via the central conduction mechanism; as a result, the cooling is not effective and the body temperature may rise suddenly [22]. Although drug cooling cannot completely inhibit temperature rise, it may play an antipyretic effect by inhibiting central prostaglandin synthesis. In our study, the drop of body temperature in groups $\mathrm{B}$ and $\mathrm{AB}$ was smaller than in group $\mathrm{A}$ after the application of cooling measures; in group $B$, the body temperature even rebounded. The cooling effectiveness was better in group $\mathrm{AB}$ than in groups $\mathrm{A}$ and $\mathrm{B}$ one hour after cooling, which might also be explained by the possibility that ice-bag cooling might not be feasible. During the cooling, the degree of body temperature rebounding or increasing was also higher in groups $\mathrm{A}$ and $\mathrm{AB}$ than in group $\mathrm{A}$; the cooling effectiveness and body temperature control effectiveness were superior in group $\mathrm{A}$ to those in groups $\mathrm{B}$ and $\mathrm{AB}$, showing significant difference [23-26].

It has been widely recognized that interventions should be provided as early as possible for fever in ACI patients; however, no consensus has been reached on how to carry out the intervention $[15,27,28]$. Fever management mode has not 
Citation: Pan S, Zhang X, Zhang Q, et al. Effectiveness of different targeted temperature management methods for fever in patients with acute cerebral infarction. J Neurol Neurorehabil Res. 2017;2(2):10-14.

been available in most hospitals, which may be due to the lack of evidences on how to treat fever effectively and whether the treatment of fever is beneficial to the patient's prognosis [29]. Clinically fever is typically assessed by nurses, who often will take the initial cooling measure (i.e., physical cooling). However, as shown by studies on fever management practices among neuroscience nurses [30-32], nurses often have not adequately grasped the definition of fever, the rational cooling methods, and the correlation between fever and secondary brain injury; thus, they cannot effectively cooperate during cooling treatment. However, improper treatment of fever can easily cause infections and prolong treatment time $[25,26]$. Ice bag is cheap and simple, and thus has been widely applied in clinical settings. However, physical cooling will cause chills and increase metabolism and oxygen consumption, which makes the cooling method become less effective and increases brain burden. In addition, research shows that the ice in ice bag has sharp edges and is easy to melt, which may cause adverse reactions such as flushed skin or discomfort in the patients; in severe cases, it may lead to local skin lesion [27]. The results of this study show that compared with ice bag alone or ice bag + ibuprofen, the effectively of ibuprofen alone in lowing body temperature and TTM was the best choice.

Our current study was limited by its small sample size. More attention should be paid to the effect of fever on the prognosis in ACI patients, in whom appropriate cooling measures should be applied based on their specific disease conditions. Meanwhile, further training should be provided to the nurses based on clinical evidences to optimize TTM. Last, the sample of patients included in this study are within a moderate severity GCS around 10, however, it is unknown whether the patient with lower GCS score responds to these measures and we need more studies on this point with more details in the future.

\section{Conclusion and Recommendations}

In this retrospective study on the commonly used cooling methods for ACI patients, the effectively of ibuprofen alone in lowing body temperature and TTM was remarkably better than ice bag alone or ice bag + ibuprofen; meanwhile, it is easy to use and has

less adverse reactions/complications. It is recommended that further large scale randomized controlled trials be performed in order to fully establish the safety and support the efficacy of erythropoietin administration in patients with traumatic brain injury.

\section{Funding}

This study was funded by Southern Medical University Nanfang hospital presidentßund Project (No.2013H003).

\section{References}

1. Seifi A, Carr K, Maltenfort M, et al. The incidence and risk factors of associated acute myocardial infarction (AMI) in acute cerebral ischemic (ACI) events in the United States. Plos One. 2014;9:e105785.

2. Saxena M, Young P, Pilcher D, et al. Early temperature and mortality in critically ill patients with acute neurological diseases: trauma and stroke differ from infection. Intens Care Med. 2015;41:1-10.
3. Li L, Zhang L, Xu W, et al. Risk assessment of ischemic stroke associated pneumonia. World J Emergen Med. 2014;5:209-13.

4. Goldstein L B. Modern medical management of acute ischemic stroke. Methodist Debakey Cardiovasc J. 2013;10:99-104.

5. Thompson HJ. Evidence-base for fever interventions following stroke. Stroke. 2015;46.

6. Hillier R, Everett B. Evaluating culture practices used to identify infection in patients with brain injury. Crit Care Nurs Q. 2012;35:228-33.

7. Rincon F, Patel U, Schorr C, et al. Brain injury as a risk factor for fever upon admission to the intensive care unit and association with in-hospital case fatality: A matched cohort study. J Intens Care Med. 2013;30:107-14.

8. Greer DM, Funk SE, Reaven NL, et al. Impact of fever on outcome in patients with stroke and neurologic injury: a comprehensive meta-analysis. Strok J Cereb Circ. 2008;39:3029-35.

9. Swarowska M, Polczak A, Pera J, et al. Hyperfibrinogenemia predicts long-term risk of death after ischemic stroke. J Thromb Thrombolysis. 2014;38:517-21.

10. Oh HS, Rn HSJ, Rn WSS. Non-infectious hyperthermia in acute brain injury patients: Relationships to mortality, blood pressure, intracranial pressure and cerebral perfusion pressure. Inter J Nurs Pract. 2012;18:295-302.

11. Hocker SE, Tian L, Li G, et al. Indicators of central fever in the neurologic intensive care unit. Jama Neur. 2013, 70:1499-1504.

12. Choi I, Hwang K, Chung C, et al. Brain temperature, body core temperature, and intracranial pressure in acute cerebral damage. J Neur Neurosur Psych. 2001;71:448-54.

13. Darwazeh R, Yan Y. Mild hypothermia as a treatment for central nervous system injuries Positive or negative effects? Neural Regene Res. 2013;8:2677-86.

14. Mcilvoy L. Fever management in patients with brain injury. Aacn Adv Crit Care. 2012;23:204-11.

15. Rincon F, Hunter K, Schorr C, et al. The epidemiology of spontaneous fever and hypothermia on admission of brain injury patients to intensive care units: A multicenter cohort study. J Neurosurg. 2014;121:1-11.

16. Yan Y, Tang W, Deng Z, et al. Cerebral oxygen metabolism and neuroelectrophysiology in a clinical study of severe brain injury and mild hypothermia. J Clin Neurosci. 2010;17:196-200.

17. Karaszewski B, Carpenter TK, Thomas RG, et al. Relationships between brain and body temperature, clinical and imaging outcomes after ischemic stroke. J Cereb Blood Flow Metab. 2013;33:1083-9.

18. Gozzoli V, Treggiari MM, Kleger GR, et al. Randomized trial of the effect of antipyresis by metamizol, propacetamol or external cooling on metabolism, hemodynamics and inflammatory response. Inten Care Med. 2004;303:401-7. 
19. Sherman JM, Sood SK. Current challenges in the diagnosis and management of fever. Curr Opin Pediatr. 2012;243:400-6.

20. Abraham E. Hot times in the intensive care unit. Crit Care. 2010;14:1-2.

21. Erlewyn LMD, Coppens K, Hunt L P, et al. Randomised controlled trial of combined paracetamol and ibuprofen for fever. Arch Dis Child. 2006;915:414-6.

22. Young PJ. Fever management in intensive care patients with infections. Criti Care. 2014;18:206-14.

23. Lanas A, Mccarthy D, Voelker M, et al. Short-term acetylsalicylic acid (aspirin) use for pain, fever, or coldsgastrointestinal adverse effects: a meta-analysis of randomized clinical trials. Drugs RD. 2011;11:277-88.

24. Mullins ME, Empey M, Jaramillo D, et al. A prospective randomized study to evaluate the antipyretic effect of the combination of acetaminophen and ibuprofen in neurological ICU patients. Neurocrit Care. 2011;153:375-8.

25. Sund-Levander M, Wahren LK. Assessment and prevention of shivering in patients with severe cerebral injury. A pilot study. J Clin Nurs. 2000;9:55-61.
26. Proulx CI, Ducharme MB, Kenny GP. Effect of water temperature on cooling efficiency durinhyperthermia in humans. J Appl Physiol. 2003;94:1317-23.

27. Lenhardt R, Negishi C, Sessler D I, et al. The effects of physical treatment on induced fever in humans. Am J Med. 1999;106:550-5.

28. Scaravilli V, Tinchero G, Citerio G. Fever management in SAH. Neurocrit Care. 2011;15:287-94.

29. Niven DJ, Léger C, Stelfox HT, et al. Fever in the critically ill: a review of epidemiology, immunology, and management. J Intensive Care Med. 2012;27:290-7.

30. Polat M, Kara S, Tezer H, et al. A current analysis of caregivers' approaches to fever and antipyretic usage. J Infect Dev Ctries. 2014;8:365-71.

31. Knowlton MC. Nurses know how to manage fever, but what about the shivering? Nurs. 2013;43:49-51.

32. Rockett H, Thompson HJ, Blissitt PA. Fever management practices of neuroscience nurses: what has changed? J Neurosci Nurs. 2015;47:66-75.

\section{*Correspondence to:}

Suyue Pan,

Department of Neurology

Nanfang Hospital, Southern Medical University

Guangzhou North Avenue 1838\#

Guangzhou 510515, China

Tel: +86 13556184981

E-mail: 15626042033@163.com 